\title{
Recent developments in understanding the mechanism and functions of microRNAs
}

\author{
Suhail Muzaffar ${ }^{1 *}$, Karishma Bisht ${ }^{2}$ \\ ${ }^{1}$ Centre for Genome Research, Department of Microbiology and Biotechnology Centre, The M. S. University of Baroda, Vadodara-390002, India. \\ ${ }^{2}$ Division of Genetics, ICAR- Indian Agricultural Research Institute, New Delhi-110012, India.
}

\section{ARTICLE INFO}

Article history:

Received on: 03/11/2016

Accepted on: 23/12/2016

Available online: 20/03/2017

\section{Key words:}

MicroRNA, MicroRNA

biogenesis, Functions of

microRNAs.

\begin{abstract}
Based on their mechanism of action and biological function, several classes of small RNAs have come into the limelight in the last two decades. These small RNA molecules generally belong to three main categories: short interfering RNAs (siRNAs), microRNAs (miRNAs), and piwi-interacting RNAs (piRNAs). miRNAs and siRNAs are distinguished primarily because miRNAs are endogenous in nature and are expressed by an organism's own genome, whereas siRNAs are exogenous in origin and derived mainly from the viruses and transposons. The first miRNA, lin-4, was discovered in 1993 as an endogenous regulator of genes that control developmental timing in Caenorhabditis elegans. miRNAs are coded by both plant and animal genomes and their transcription is typically performed by RNA polymerase II. MicroRNAs repress the expression of many genes by accelerating messenger RNA degradation as well as translational inhibition, thereby reducing the level of protein. Due to their involvement in various diseases like cancer, miRNAs have been a focus of scientific research for their potential as a new generation of drugs. The recent findings in miRNA research have been summarized in this review to add new dimensions to miRNA mechanism and functions.
\end{abstract}

\section{INTRODUCTION}

MicroRNAs (miRNAs) are small, evolutionary conserved, non-coding RNA molecules which mediate the posttranscriptional gene silencing in plants, animals, and some viruses. These $\sim 22$ nucleotide molecules repress the expression of various genes by messenger RNA degradation or by inhibiting the mRNA translation [1]. miRNAs look similar to small interfering RNAs (siRNAs), except that siRNA are exogenously introduced into the cell while as miRNA are endogenously produced from the regions of RNA transcripts that fold back on themselves and generate short hairpin structures [2]. miRNAs are well conserved throughout the plant and animal kingdom and are of high evolutionary significance. The human genome has been estimated to encode more than a thousand miRNAs that can target the expression of nearly $60 \%$ of the genes [1].

\footnotetext{
* Corresponding Author

Suhail Muzaffar, National Centre for Biological Sciences GKVK Campus, Bellary Road Bangalore 560065 INDIA.

Email: suhail.bt @ gmail.com; Phone: +919898726492
}

Dysregulation of miRNAs has been linked to different human diseases including cancer, cardiovascular diseases, metabolic disorders and viral infections [3].

In this review, we have summarized the existing information related to the discovery, mechanism, functions, and dysregulation of miRNAs.

\section{DISCOVERY OF MIRNA}

The process of RNA interference was largely unknown until Andrew Fire and Craig C. Mello discovered that the doublestranded RNA (dsRNA) is a potent trigger for gene silencing [4]. They injected a dsRNA 742-nucleotide segment of UNC22 gene into the body of an adult C. elegans. Unc22 codes for a myofilament protein and the decrease in Unc22 expression causes a characteristic twitching phenotype. The dsRNA injected nematodes showed the normal twitching, but the progeny showed a strong twitching phenotype suggesting the silencing in Unc22 (Fig 1). They also demonstrated the sense strand silencing observed by Guo and Kemphues was actually due to the doublestranded RNA contamination in the samples used in the experiments. Fire and Mello were awarded the 2006 Nobel Prize in Physiology or Medicine for the discovery of RNA interference. 


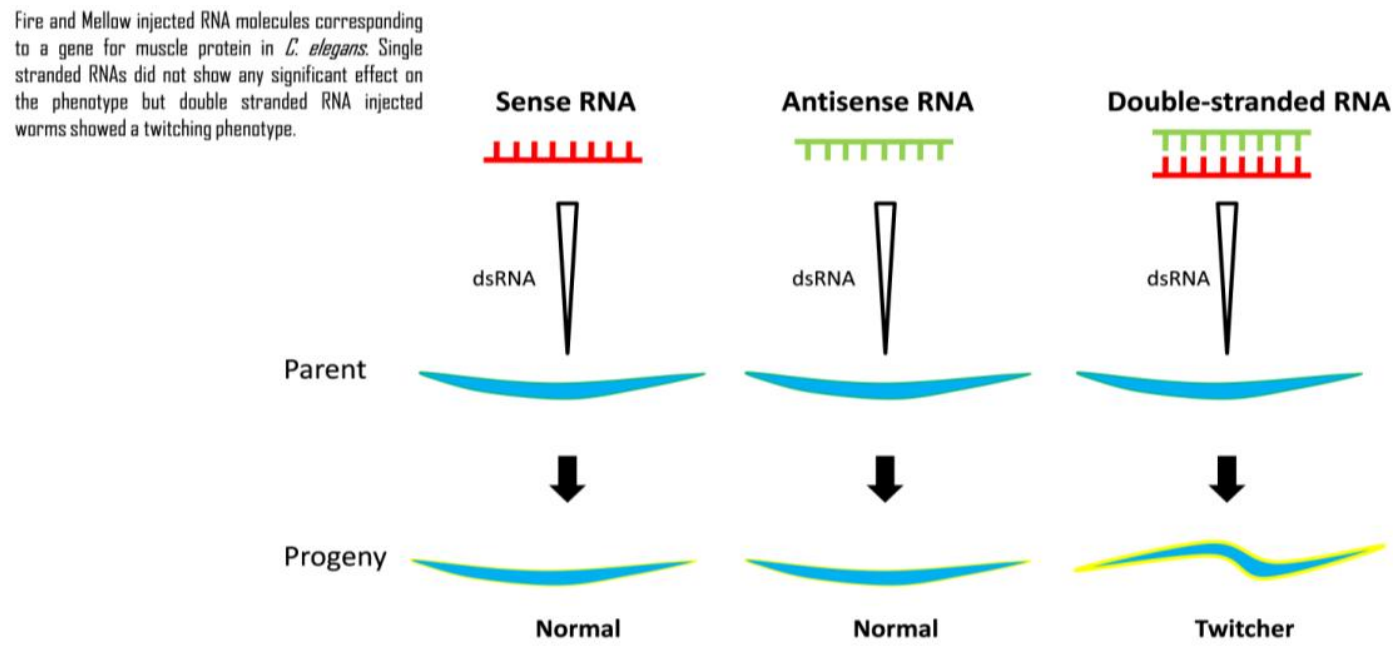

Fig. 1: Discovery of RNA interference. Andrew Fire and Craig Mello injected double stranded RNA molecules encoding a muscle protein Unc22 in C. elegans and observed that the worms developed a peculiar twitching phenotype. This behavior was caused by the silencing of the native Unc22 gene.

Several proteins involved in the process of RNAi were discovered from the genetic screens in C. elegans [5]. Most of the proteins involved in the dsRNA-mediated gene silencing in $C$. elegans were found to have homologs in Drosophila, Fungi, and Plants, which established a common basic mechanism of RNAi. In 2001, Zamore and his colleagues observed that 21-23 nt RNAs produced from dsRNA in cell extracts of Drosophila could serve as the silencing trigger for RNAi in cell extracts without dsRNA treatments [6]. Later it was found that these 21-23 nt small RNAs are generated by a ribonuclease present in the RNA-induced silencing complex (RISC) [7]. Dicer, a highly conserved RNase III enzyme involved in the cleavage of small RNAs was first cloned in 2001[8]. One of the exciting observations in gene silencing was that naturally occurring micro RNA (miRNA) are also processed by Dicer and function through the common RNAi machinery [9, 10]. In 1993, the first miRNA Lin-4 was discovered in C. elegans in the laboratories of Victor Ambros and Gary Ruvkun [11]. lin-4 miRNA specifically binds to multiple target sites in the 3'UTR region of lin-14 and negatively regulates its expression. Another miRNA, let-7 which is a heterochronic gene of C. elegans was discovered in 2000, seven years after the discovery of the first miRNA. It was reported that let-7 is a $21 \mathrm{nt}$ long RNA molecule controlling L4-to-adult transition during the larval development [12]. The discovery that let-7 miRNA is conserved across many species initiated a wide search for microRNAs in various organisms. Presently thousands of miRNAs have been identified in humans and other species. Numerous miRNA prediction tools, such as miRbase database, have facilitated the prediction of miRNA and their target genes in different organisms.

\subsection{Mechanism of miRNA-mediated gene silencing 2.1.1. Initiation}

Gene silencing by miRNA may occur either by mRNA degradation or preventing mRNA translation. RNAi machinery can be triggered by RNA molecule generated from a variety of sources. Primary miRNA or pri-miRNA, which serves as a source of endogenous dsRNA, folds on itself and forms a double-stranded stem-loop structure. Some microRNA precursors located in the intergenic regions are transcribed by the gene promoters, while others clustered in the polycistronic transcripts are driven by their own promoters [13]. miRNA precursors are mainly transcribed by RNA polymerase II and infrequently by RNA polymerase III [14, 15]. The conversion of nascent pre-miRNA into mature miRNA takes place in two steps. First, the primary miRNA transcripts (primiRNA) are processed to form $\sim 70$ nt pre-miRNA. Then the premiRNA is further chopped to generate 21- 25 nucleotide mature miRNAs [16] (Fig. 2). The two chronological steps of miRNA maturation are executed by two dsRNA-specific endonucleases Drosha and Dicer. These enzymes cleave dsRNA in a specific manner and thus generating 3' overhang nucleotides and 5' phosphate groups. Drosha in association with another protein "Pasha" (DGCR8), recognizes the pri-miRNA and excises its stem-loop structure inside the nucleus. A Ran-GTP dependent transporter, exportin-5 transports the pre-miRNAs from the nucleus into the cytoplasm [17]. Once the pre-miRNA enters the cytoplasm, the Dicer will trim off its loop and process it into a mature microRNA [18]. The processing of exogenously introduced dsRNA involves Dicer but not Drosha and Pasha. Dicer is endoribonuclease from the RNase III family which cuts dsRNA and pre-microRNA (pre-miRNA) into double-stranded siRNA and miRNA, respectively. It is a complex protein that contains a dsRNA binding domain, a helicase domain, two RNase III domains, and a Piwi/Argonaute domain [19]. In humans, the protein is encoded by the DICERI gene containing helicase and PAZ (Piwi/Argonaute/Zwille) domains [20]. The PAZ domain binds to the 3' overhang of dsRNA and the RNaseIII catalytic domains initiate the cleavage of the RNA strands [21]. Dicer associates with the existing terminus of dsRNA and cleaves $\sim 21$ nucleotides from the end thus forming a fresh end with two 3' overhangs. Due to the continuous terminal cleaving of dsRNA, a pool of 21-nt long small RNA with two 3'overhangs nucleotides are generated. 


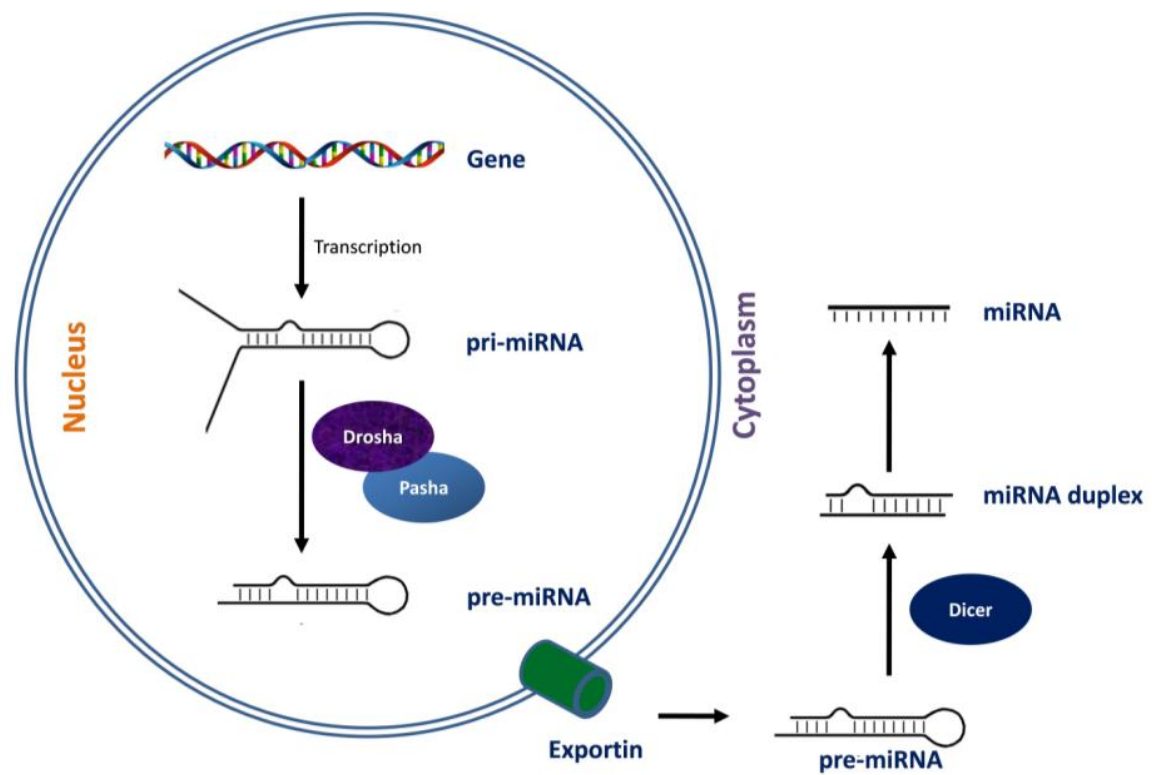

Fig. 2: Representative scheme of biogenesis of microRNAs. Inside the nucleus, the pri-miRNA transcripts are processed by Drosha into pre-miRNAs. Exportin5 transports pre-miRNA into the cytoplasm where they are processed by Dicer. One of the strands of the miRNA duplex is loaded into RISC and guides the complex towards the target mRNA.

\subsubsection{Assembly of RNA-induced silencing complex (RISC)}

The miRNAs, generated due to the activity of dicer, assemble with the ribonucleoprotein complex called as RNAinduced silencing complex (RISC). RISC incorporates one strand of a single-stranded RNA (ssRNA) like miRNA or double stranded siRNA and uses it as a guide to suppress the expression of a specific mRNA [22]. RISC complex is composed of different proteins and the most conserved members are Argonaute proteins, which play a central role in the activity of this complex. Argonaute proteins are involved in degradation of the target mRNA strand complementary to the bound siRNA [23]. Structural analysis demonstrated that PIWI domain is a possible functional domain of Argonaute protein as it possesses the RNase H activity [24]. The numbers of Ago proteins varies from organism to organism and ranges from one in S.pombe to over twenty in C.elegans [25]. There are eight Ago proteins present in humans but only Ago-2 has the active catalytic domain involved in the RNA cleavage function [26].

\subsubsection{Effector stage}

Most of the data suggest that effector stage of miRNAmediated post-transcriptional gene silencing takes place in the cytoplasm and P-bodies. Double-stranded microRNA is a transient imperfect duplex molecule consisting of a passenger strand and a mature guide. The RNA duplex is unwound and the guide strand is incorporated into the RISC protein complex to direct the complex towards target mRNA. In Drosophila, the RISC assembly model involves ATP-dependent unwinding of RNA duplexes thus enabling the guide strand to load into Ago2 of the RISC complex leading to its activation. The process of miRNA duplex unwinding is followed by subsequent degradation of the passenger strand by Ago2 [27]. Whether passenger strand degradation occurs prior to
RISC loading is not clear. The key feature of binding of miRNA and target mRNA involves the Watson-Crick base pairing between the guide strand and the 3'UTR of the target. Most plant miRNAs bind to the coding sequence of target mRNAs with a near-perfect complementarity. On the other hand, animal miRNAs have been observed to bind the target mRNA with lots of mismatches and bulges. The degree of miRNA-mRNA complementarity is a key determinant of the gene regulation. The perfect complementarity allows Ago-catalyzed degradation of the mRNA strand, as the central mismatches promote repression of mRNA translation rather than mRNA cleavage [1]. It has been observed that miRNAdirected mRNA degradation is catalyzed by Ago2 when the miRNA and target are extensively base-paired in the seed region and 10-11 bases of the guide strand [26].

In addition to the slicer activity, miRNA can accelerate the target mRNA deadenylation and decapping thus affecting the translation initiation and transcript stability [28]. Translation is also indirectly regulated by spatial separation of miRNA-targeted mRNA complex from translational machinery into the cytoplasmic P-bodies, also known as processing bodies [29]. The function of Pbodies is very crucial for the miRNA activity as the inhibition of P-body formation by depletion of GW182, which is a major component of P-bodies, impairs miRNA function [30, 31]. Active miRNA-RISC complex directs the mRNA awaiting translation or being translated to the P-body, where the degree of miRNA-target complementarity will determine the slicer-dependent or slicerindependent gene silencing.

\subsection{Functions of micro RNAs}

The key function of miRNAs is to inhibit the protein synthesis either by inhibition of translation or by mRNA degradation. A study based on ribosome profiling to study an 
overall effect on protein production as well as mRNA expression levels revealed that mRNA destabilization is a predominant miRNA silencing mechanism rather that inhibition of translation [32]. Not only mRNAs repression, miRNAs have also been discovered to activate translation of targeted mRNAs [33]. It was clearly demonstrated that under the serum starvation conditions, TNF $\alpha$ AU-rich elements recruit miR369-3 to mediate translational upregulation. On the other hand, in the case of synchronized proliferating cells, miR369-3 caused repression of translation. Similarly, during the cell cycle arrest let-7 microRNA induces translation whereas it represses translation in case of proliferating cells. Therefore, miRNAs can switch between translation activation and repression depending on the phase of cell cycle. Many miRNA have been functionally characterized in both animals and plants and have been demonstrated to be involved in various functions. Some of the examples are described below.

\subsection{1. miRNAs in Animals}

MicroRNAs play an important role in the regulation of biological functions in animals and regulate the expression of genes at various stages of development. In the case of animals, miRNAs exhibit a limited complementarity with their target mRNAs, but still exhibit a firm control over most of the physiological processes. They have been reported to repress the initiation step of the translation process, which is followed by mRNA degradation [34]. Loss-of-function mutants of the first two identified miRNAs in C. elegans, lin-4 and let-7 showed defects in larvae development [11, 12]. lin-4 mainly regulates the early development in C. elegans, whereas let-7 is involved in late developmental processes. In Drosophila melanogaster, many functional miRNA have been discovered. Overexpression of bantam, a Drosophila miRNA, has been demonstrated to have antiapoptotic and pro-proliferative activities [35]. In mammals, a muscle-specific miRNA, miR-1, targets HAND2 (heart and neural crest derivatives-expressed protein 2) and results in premature differentiation and muscle degeneration of cardiomyocytes [36]. Certain miRNAs like miR-375 control various physiological processes of an organism. miR-375 inhibits glucose-induced insulin secretion by regulating its target gene Myotrophin, suggesting that miR-375 is an inhibitor of glucose-stimulated insulin secretion [37]. On the other hand, miR-375 is also highly expressed in the pituitary gland of zebrafish, indicating its possible role in the secretion of hormones. Several of the known miRNA in animals and their functions have been listed in Table 1.
Several miRNAs have been demonstrated to have essential roles in normal lung development and different lung diseases [38, 39]. The lung diseases that have been associated with different miRNAs include Asthma, chronic obstructive pulmonary disease (COPD), Cystic fibriosis and lung cancer [39, 40].

\subsection{2. miRNAs in plants}

Like animals, miRNAs play a critical role in the regulation of growth and development of plants. However unlike animal miRNAs, plant miRNAs show high complementarity with the target mRNAs, which makes prediction and identification of miRNAs easy. In plants, miRNA mainly targets transcription factors and F-box proteins, which form the major plant developmental network [41]. The significance of miRNAs in plant growth and development was discovered from the analysis of mutants impaired in small RNA biogenesis. These mutants show a number of developmental defects including the altered growth patterns. Accumulation of target gene expression was demonstrated in the absence of miRNA activity. miR-165/166 regulates the expression of prohibitin (PHB) in Arabidopsis and RLD1 in maize. Mutations in the miR-165/166 complementary site in RLD1 causes an accumulation of RLD1-mRNA, suggesting the role of miRNAs in the regulation of genes involved in the development of maize [42]. In Arabidopsis, APETALA2 (AP2) regulates the developmental timing of flowers. AP2 gene expression, in turn, is regulated by miR-172 microRNA. The overexpression of miR-172 causes the loss-of-function of AP2 thus showing floral developmental defects such as the absence of petals and transformation of sepals into carpels [43]. Floral initiation, as well as floral development, is controlled by the plant hormone gibberellin (GA). GAMYB mediates gibberellic aciddependent pathway in plants and regulates GA-activated genes. GA regulates miR-159 activity and miR-159 directs the cleavage of mRNA encoding GAMYB-related proteins like MYB33 and MYB65 [44]. Overexpression of miR-159 causes the late flowering phenotype, whereas plants expressing the miRNAresistant version of MYB33 leads to developmental defects like hyponastic leaves $[45,46]$. Some of the known plant microRNA and their functions have been listed in Table 2. Genome wide screening of rice led to discovery of different miRNAs including osmiR397 in rice seeds [47]. It was demonstrated that overexpression of the two forms of this miRNA lead to 7.4 and $13.4 \%$ increase in 1,000-grain weight, along with the increase in grain size [48].

Table 1: MicroRNAs and their functions in animals.

\begin{tabular}{ccccc}
\hline miRNA & Target gene & Function & Organism \\
\hline lin-4 & lin-14, lin-28 & Larval development & C. elegans \\
let-7 & lin-41 & Larval developmental timing & C. elegans \\
bantam & HID & Proliferative and antiapoptotic & D. melanogaster \\
miR-1 & HAND 2 & Cardiomyocyte differentiation & Mus musculus \\
miR-7 & Notch targets & Notch signaling & D. melanogaster \\
miR-375 & Myotrophin & Insulin secretions & M. musculus & {$[12]$} \\
miR-32 & Retrovirus PFV1 & Antiviral defense & H.sapiens & {$[36]$} \\
miR-146 & c-Myc, ROCK1 & Immune system & H.sapiens & H.sapiens \\
miR-223 & NFI-A & Granulocytic maturation & {$[37]$} & {$[60]$} \\
\hline
\end{tabular}


Table 2: MicroRNAs and their functions in plants.

\begin{tabular}{|c|c|c|c|c|}
\hline miRNA & Target gene & Function & Organism & Reference \\
\hline $\operatorname{miR} 156$ & SPL & Developmental transition time & A. thaliana & {$[63]$} \\
\hline $\operatorname{miR} 160$ & ARF10 & Signal transduction & A. thaliana & [64] \\
\hline $\operatorname{miR} 164$ & NAC-TF & Root and shoot development & A. thaliana & [65] \\
\hline $\operatorname{miR} 157$ & SPL & Developmental timing & G. hirsutum & [66] \\
\hline $\operatorname{miR} 172$ & AP2 & Floral development & O. sativa & [43] \\
\hline $\operatorname{miR} 319$ & TCP & Leaf development & A. thaliana & {$[67]$} \\
\hline $\operatorname{miR} 390$ & TAS3 & Auxin response & Z. mays & [68] \\
\hline $\operatorname{miR} 393$ & TIR1 & Hormone signaling & A. thaliana & [41] \\
\hline miR394 & F-Box & Hormone signaling & A. thaliana & [69] \\
\hline miR399 & At2g33770 & Ubiquitin conjugation & A. thaliana & {$[70]$} \\
\hline
\end{tabular}

\subsection{Role of miRNAs in diseases}

MicroRNAs represent the critical regulators of gene expression in addition to the transcriptional control. miRNAs regulate the various phases of cell development and the dysregulation of miRNA function can lead to various disorders. Some of the common examples of such disorders include hereditary progressive hearing loss in miR-96 [49]. The first disease to be associated with miRNA dysregulation in humans was chronic lymphocytic leukemia [50]. One of the major underlying causes of cancer is DNA damage and lack of repair system. If a cell is deficient in DNA damage repair, the mutations accumulate and cause epigenetic alterations. Such accumulated mutations and epigenetic alterations can lead to cancer. Altered expression of microRNAs leading to DNA repair deficiencies is often associated with cancers. Almost $15 \%$ of deficiencies in MLH1 (a DNA repair protein) in sporadic colon cancers are caused by the overexpression of the microRNA miR-155, which represses MLH1 protein expression

MicroRNA expression profiling studies have demonstrated that the expression profile of specific miRNAs alter during heart diseases in humans, therefore, indicating their role in cardiomyopathy [51]. MicroRNA-712 is a potential biomarker of atherosclerosis, a cardiovascular disease associated with lipid retention and inflammation in arterial wall [52]. miRNAs play a critical role in the differentiation of stem cell progenitors into the adipocytes [53]. Decreased expression of miR-155, miR-121 and miR-122 has been observed during the adipogenic differentiation, suggesting that they act as negative regulators of differentiation. MicroRNAs have been linked to various growth and developmental defects in humans. Deletion of the miR-17 92 cluster has been associated with skeletal and growth defects in humans [54]. miRNAs also regulate the development of nervous system and neural miRNAs like miR-124, miR-132, miR-134 and miR138 have been shown to be involved in the synaptic development and synapse maturation [55, 56]. Various other nervous disorders like bipolar disorder, schizophrenia, and anxiety disorders have also been associated with miRNA expression [57].

\section{CONCLUSIONS}

After their discovery in 1993, miRNAs became an exciting area of research to elucidate their mechanism of action and function in various organisms. Since the discovery of
miRNAs, there was a huge shift of research from coding to noncoding DNA. MicroRNAs are highly conserved non-coding RNA molecules which regulate the expression of different genes at various levels. The regulatory functions of these small RNA molecules are carried out mainly through the RNA-induced silencing complex. In both plants and animals, numerous miRNAs and their targets have been discovered and many vital functions in growth and development have been attributed to them. There are evidences that miRNA dysregulation is associated with various diseases notably cancer and heart diseases. MiRNAs are currently under extensive research for future applications in cancer diagnosis, prognosis and treatment.

\section{Financial support and sponsorship: Nil.}

Conflict of Interests: There are no conflicts of interest.

\section{REFERENCES}

1. RW CarthewEJ Sontheimer. Origins and mechanisms of miRNAs and siRNAs. Cell. 2009; 136: 642-655

2. DP Bartel. MicroRNAs: genomics, biogenesis, mechanism, and function. cell. 2004; 116: 281-297

3. MI Almeida, RM Reis, GA Calin. MicroRNA history: discovery, recent applications, and next frontiers. Mutation Research/Fundamental and Molecular Mechanisms of Mutagenesis. 2011; 717: $1-8$

4. A Fire, S Xu, MK Montgomery, SA Kostas, SE Driver, CC Mello. Potent and specific genetic interference by double-stranded RNA in Caenorhabditis elegans. Nature. 1998; 391: 806-811

5. H Tabara, M Sarkissian, WG Kelly, J Fleenor, A Grishok, L Timmons, A Fire, CC Mello. The rde-1 gene, RNA interference, and transposon silencing in C. elegans. Cell. 1999; 99: 123-132

6. PD Zamore, T Tuschl, PA Sharp, DP Bartel. RNAi: double-stranded RNA directs the ATP-dependent cleavage of mRNA at 21 to 23 nucleotide intervals. Cell. 2000; 101: 25-33

7. SM Hammond, E Bernstein, D Beach, GJ Hannon. An RNA-directed nuclease mediates post-transcriptional gene silencing in Drosophila cells. Nature. 2000; 404: 293-296

8. E Bernstein, AA Caudy, SM Hammond, GJ Hannon. Role for a bidentate ribonuclease in the initiation step of RNA interference. Nature. 2001; 409: 363-366

9. RF Ketting, SE Fischer, E Bernstein, T Sijen, GJ Hannon, RH Plasterk. Dicer functions in RNA interference and in synthesis of small RNA involved in developmental timing in C. elegans. Genes \& development. 2001; 15: 2654-2659

10. A Grishok, AE Pasquinelli, D Conte, N Li, S Parrish, I Ha, DL Baillie, A Fire, G Ruvkun, CC Mello. Genes and mechanisms related to RNA interference regulate expression of the small temporal RNAs that control C. elegans developmental timing. Cell. 2001; 106: 23-34 
11. RC Lee, RL Feinbaum, V Ambros. The C. elegans heterochronic gene lin-4 encodes small RNAs with antisense complementarity to lin-14. Cell. 1993; 75: 843-854

12. BJ Reinhart, FJ Slack, M Basson, AE Pasquinelli, JC Bettinger, AE Rougvie, HR Horvitz, G Ruvkun. The 21-nucleotide let-7 RNA regulates developmental timing in Caenorhabditis elegans. Nature. 2000; 403: 901-906

13. M Lagos-Quintana, R Rauhut, J Meyer, A Borkhardt, T Tuschl. New microRNAs from mouse and human. RNA. 2003; 9: 175-179

14. Y Lee, M Kim, J Han, KH Yeom, S Lee, SH Baek, VN Kim. MicroRNA genes are transcribed by RNA polymerase II. The EMBO journal. 2004; 23: 4051-4060

15. GM Borchert, W Lanier, BL Davidson. RNA polymerase III transcribes human microRNAs. Nature structural \& molecular biology. 2006; 13: 1097-1101

16. Y Lee, K Jeon, JT Lee, S Kim, VN Kim. MicroRNA maturation: stepwise processing and subcellular localization. The EMBO journal. 2002; 21: 4663-4670

17. E Lund, S Güttinger, A Calado, JE Dahlberg, U Kutay. Nuclear export of microRNA precursors. Science. 2004; 303: 95-98

18. G Hutvágner, J McLachlan, AE Pasquinelli, É Bálint, T Tuschl, PD Zamore. A cellular function for the RNA-interference enzyme Dicer in the maturation of the let-7 small temporal RNA. Science. 2001; 293: $834-838$

19. SM Hammond. Dicing and slicing. FEBS letters. 2005; 579: 5822 5829

20. S Matsuda, Y Ichigotani, T Okuda, T Irimura, S Nakatsugawa, M Hamaguchi. Molecular cloning and characterization of a novel human gene (HERNA) which encodes a putative RNA-helicase. Biochimica et Biophysica Acta (BBA)-Gene Structure and Expression. 2000; 1490: 163-169

21. IJ MacRae, K Zhou, F Li, A Repic, AN Brooks, WZ Cande, PD Adams, JA Doudna. Structural basis for double-stranded RNA processing by Dicer. Science. 2006; 311: 195-198

22. W Filipowicz, SN Bhattacharyya, N Sonenberg. Mechanisms of posttranscriptional regulation by microRNAs: are the answers in sight? Nature Reviews Genetics. 2008; 9: 102-114

23. RI Gregory, TP Chendrimada, N Cooch, R Shiekhattar. Human RISC couples microRNA biogenesis and posttranscriptional gene silencing. Cell. 2005; 123: 631-640

24. J-B Ma, K Ye, DJ Patel. Structural basis for overhang-specific small interfering RNA recognition by the PAZ domain. Nature. 2004; 429: 318-322

25. MA Carmell, Z Xuan, MQ Zhang, GJ Hannon. The Argonaute family: tentacles that reach into RNAi, developmental control, stem cell maintenance, and tumorigenesis. Genes \& development. 2002; 16: $2733-2742$

26. G Meister, M Landthaler, A Patkaniowska, Y Dorsett, G Teng, T Tuschl. Human Argonaute2 mediates RNA cleavage targeted by miRNAs and siRNAs. Molecular cell. 2004; 15: 185-197

27. V Ambros. The functions of animal microRNAs. Nature. 2004; 431: 350-355

28. L Wu, J Fan, JG Belasco. MicroRNAs direct rapid deadenylation of mRNA. Proceedings of the National Academy of Sciences of the United States of America. 2006; 103: 4034-4039

29. M Brengues, D Teixeira, R Parker. Movement of eukaryotic mRNAs between polysomes and cytoplasmic processing bodies. Science. 2005; 310: 486-489

30. J Liu, FV Rivas, J Wohlschlegel, JR Yates, R Parker, GJ Hannon. A role for the P-body component GW182 in microRNA function. Nature cell biology. 2005; 7: 1261-1266

31. A Jakymiw, S Lian, T Eystathioy, S Li, M Satoh, JC Hamel, MJ Fritzler, EK Chan. Disruption of GW bodies impairs mammalian RNA interference. Nature cell biology. 2005; 7: 12671274

32. H Guo, NT Ingolia, JS Weissman, DP Bartel. Mammalian microRNAs predominantly act to decrease target mRNA levels. Nature. 2010; 466: 835-840
33. S Vasudevan, Y Tong, JA Steitz. Switching from repression to activation: microRNAs can up-regulate translation. Science. 2007; 318: 1931-1934

34. M KatoFJ Slack. microRNAs: small molecules with big roles- $C$. elegans to human cancer. Biology of the Cell. 2008; 100: 71-81

35. R Nolo, CM Morrison, $\mathrm{C}$ Tao, $X$ Zhang, G Halder. The bantam microRNA is a target of the hippo tumor-suppressor pathway. Current Biology. 2006; 16: 1895-1904

36. Y Zhao, E Samal, D Srivastava. Serum response factor regulates a muscle-specific microRNA that targets Hand2 during cardiogenesis. Nature. 2005; 436: 214-220

37. MN Poy, L Eliasson, J Krutzfeldt, S Kuwajima, X Ma, PE MacDonald, S Pfeffer, T Tuschl, N Rajewsky, P Rorsman. A pancreatic islet-specific microRNA regulates insulin secretion. Nature. 2004; 432: 226-230

38. H Rupani, $\mathrm{T}$ Sanchez-Elsner, $\mathrm{P}$ Howarth. MicroRNAs and respiratory diseases. European Respiratory Journal. 2013; 41: 695705

39. S Maltby, M Plank, HL Tay, A Collison, PS Foster. Targeting MicroRNA function in respiratory diseases: mini-review. Frontiers in physiology. 2016; 7:

40. F Sonneville, M Ruffin, L Guillot, N Rousselet, P Le Rouzic, H Corvol, O Tabary. New insights about miRNAs in cystic fibrosis. The American journal of pathology. 2015; 185: 897-908

41. R SunkarJ-K Zhu. Novel and stress-regulated microRNAs and other small RNAs from Arabidopsis. The Plant Cell. 2004; 16: 2001-2019

42. MT Juarez, JS Kui, J Thomas, BA Heller, MC Timmermans. microRNA-mediated repression of rolled leaf1 specifies maize leaf polarity. Nature. 2004; 428: 84-88

43. MJ AukermanH Sakai. Regulation of flowering time and floral organ identity by a microRNA and its APETALA2-like target genes. The Plant Cell. 2003; 15: 2730-2741

44. P Achard, A Herr, DC Baulcombe, NP Harberd. Modulation of floral development by a gibberellin-regulated microRNA. Development. 2004; 131: 3357-3365

45. R Schwab, JF Palatnik, M Riester, C Schommer, M Schmid, D Weigel. Specific effects of microRNAs on the plant transcriptome. Developmental cell. 2005; 8: 517-527

46. AA MillarF Gubler. The Arabidopsis GAMYB-like genes, MYB33 and MYB65, are microRNA-regulated genes that redundantly facilitate anther development. The Plant Cell. 2005; 17: 705-721

47. Y-C Zhang, Y Yu, C-Y Wang, Z-Y Li, Q Liu, J Xu, J-Y Liao, X-J Wang, L-H Qu, F Chen. Overexpression of microRNA OsmiR397 improves rice yield by increasing grain size and promoting panicle branching. Nature biotechnology. 2013; 31: 848-852

48. C LiB Zhang. MicroRNAs in control of plant development. Journal of Cellular Physiology. 2016; 231: 303-313

49. Á Mencía, S Modamio-Høybjør, N Redshaw, M Morín, F MayoMerino, L Olavarrieta, LA Aguirre, I del Castillo, KP Steel, T Dalmay. Mutations in the seed region of human miR-96 are responsible for nonsyndromic progressive hearing loss. Nature genetics. 2009; 41: 609-613

50. K MusilovaM Mraz. MicroRNAs in B-cell lymphomas: how a complex biology gets more complex. Leukemia. 2015; 29: 1004 1017

51. T Thum, P Galuppo, C Wolf, J Fiedler, S Kneitz, LW van Laake, PA Doevendans, CL Mummery, J Borlak, A Haverich. MicroRNAs in the human heart a clue to fetal gene reprogramming in heart failure. Circulation. 2007; 116: 258-267

52. W Insull. The pathology of atherosclerosis: plaque development and plaque responses to medical treatment. The American journal of medicine. 2009; 122: S3-S14

53. JM Romao, W Jin, MV Dodson, GJ Hausman, SS Moore MicroRNA regulation in mammalian adipogenesis. Experimental Biology and Medicine. 2011; 236: 997-1004

54. L de Pontual, E Yao, P Callier, L Faivre, V Drouin, S Cariou, A Van Haeringen, D Geneviève, A Goldenberg, M Oufadem. Germline deletion of the miR-17 [sim] 92 cluster causes skeletal and growth defects in humans. Nature genetics. 2011; 43: 1026-1030 
55. ND Amin, G Bai, JR Klug, D Bonanomi, MT Pankratz, WD Gifford, CA Hinckley, MJ Sternfeld, SP Driscoll, B Dominguez. Loss of motoneuron-specific microRNA-218 causes systemic neuromuscular failure. Science. 2015; 350: 1525-1529

56. G Schratt. microRNAs at the synapse. Nature Reviews Neuroscience. 2009; 10: 842-849

57. LG Hommers, $\mathrm{K}$ Domschke, J Deckert. Heterogeneity and individuality: microRNAs in mental disorders. Journal of Neural Transmission. 2015; 122: 79-97

58. J Brennecke, DR Hipfner, A Stark, RB Russell, SM Cohen. bantam encodes a developmentally regulated microRNA that controls cell proliferation and regulates the proapoptotic gene hid in Drosophila. Cell. 2003; 113: 25-36

59. EC Lai, B Tam, GM Rubin. Pervasive regulation of Drosophila Notch target genes by GY-box-, Brd-box-, and K-box-class microRNAs. Genes \& development. 2005; 19: 1067-1080

60. C-H Lecellier, P Dunoyer, K Arar, J Lehmann-Che, S Eyquem, C Himber, A Saïb, O Voinnet. A cellular microRNA mediates antiviral defense in human cells. Science. 2005; 308: 557-560

61. T-C Chang, D Yu, Y-S Lee, EA Wentzel, DE Arking, KM West, CV Dang, A Thomas-Tikhonenko, JT Mendell. Widespread microRNA repression by Myc contributes to tumorigenesis. Nature genetics. 2008; 40: 43-50

62. F Fazi, A Rosa, A Fatica, V Gelmetti, ML De Marchis, C Nervi, I Bozzoni. A minicircuitry comprised of microRNA-223 and transcription factors NFI-A and $\mathrm{C} / \mathrm{EBP} \alpha$ regulates human granulopoiesis. Cell. 2005; 123: 819-831

63. J-W Wang, R Schwab, B Czech, E Mica, D Weigel. Dual effects of miR156-targeted SPL genes and CYP78A5/KLUH on plastochron length and organ size in Arabidopsis thaliana. The Plant Cell. 2008; 20: $1231-1243$

64. AC Mallory, DV Dugas, DP Bartel, B Bartel. MicroRNA regulation of NAC-domain targets is required for proper formation and separation of adjacent embryonic, vegetative, and floral organs. Current Biology. 2004; 14: 1035-1046
65. H-S Guo, Q Xie, J-F Fei, N-H Chua. MicroRNA directs mRNA cleavage of the transcription factor NAC1 to downregulate auxin signals for Arabidopsis lateral root development. The Plant Cell. 2005; 17: 1376-1386

66. CX Qiu, FL Xie, YY Zhu, K Guo, SQ Huang, L Nie, ZM Yang. Computational identification of microRNAs and their targets in Gossypium hirsutum expressed sequence tags. Gene. 2007; 395: 4961

67. JF Palatnik, E Allen, X Wu, C Schommer, R Schwab, JC Carrin gton, D Weigel. Control of leaf morphogenesis by microRNAs. Nature. 2003; 425: 257-263

68. B Zhang, X Pan, TA Anderson. Identification of 188 conserved maize microRNAs and their targets. Febs Letters. 2006; 580: 3753 3762

69. MW Jones-RhoadesDP Bartel. Computational identification of plant microRNAs and their targets, including a stress-induced miRNA. Molecular cell. 2004; 14: 787-799

70. E Allen, Z Xie, AM Gustafson, JC Carrington. microRNA-directed phasing during trans-acting siRNA biogenesis in plants. Cell. 2005; 121: $207-221$

\section{How to cite this article:}

Muzaffar S, Bisht K. Recent developments in understanding the mechanism and functions of microRNAs. J App Biol Biotech. 2017; 5 (02): 001-007. DOI: 10.7324/JABB.2017.50201 